1 ANALYTICAL SCIENCE

2 \& TECHNOLOGY

Vol. 27, No. 3, 153-160, 2014

http://dx.doi.org/10.5806/AST.2014.27.3.153

\title{
A study on the quantitation of asbestos by the visual estimation and point counting method
}

\author{
Yun-Ho Choi ${ }^{\star}$, Tae-Hwa Kim, Yong-Soo Bae, Tae-Hyun Kim, Hyeon-Ja Kim,
} Eun-Ah Jang and Beom-Goo Hwang ${ }^{1}$

Life Environment Team, Gyeonggi-do Institute of Health \& Environment, Suwon-si, Gyeonggi-do 440-290, Korea

${ }^{1}$ Korea Testing \& Research Institute, Gimpo-si, Gyeonggi-do 451-873, Korea

(Received Juen 4, 2013; Revised May 26, 2014; Accepted May 26, 2014)

\section{시야평가법과 포인트계수법에 의한 석면정량평가 연구}

\author{
최윤호` · 김태화 · 배용수 · 김태현 · 김현자 · 장은아 · 황범구 ${ }^{1}$ \\ 경기도보건환경연구원 생활환경팀, ${ }^{1}$ 한국화학융합시험연구원 \\ (2013. 6. 4. 접수, 2014. 5. 26. 수정, 2014. 5. 26. 승인)
}

\begin{abstract}
While variety of cases of studies about asbestos analysis methods are released internationally, the results of Asbestos Containing Materials (ACM) according to differences in the method of the analysis is becoming an issue. In this study, homogeneity ensured ACM samples were analyzed by visual estimation method and point counting method, and the result cound be used not only to improve the reliability on asbestos analysis of the institutions and analysts but also to obtain the basic data of Polarizing Light Microscope (PLM) analysis by comparing and evaluating. Asbestos analysis were divided into qualitative and quantitative analysis method. The quantitative analysis was performed by visual estimation method and point counting method (total 400 points) of EPA 600-R-93-116 method by using PLM. Firstly, The following was the result of homogeneity of the samples by ANOVA (Analysis of variance) and the results were satisfied. The results of qualitative analysis showed that the samples were chrysotile and amosite, and about the results of quantitative analysis, asbestos concentration determined by point counting method tend to be lower than concentrations determined by visual estimation method and also, pont counting method was a little more complicated and time-consuming.

요 약: 세계적으로 석면분석방법에 관한 다양한 연구사례가 발표되고 있는 가운데, 분석방법의 차이에 따른 석면함유물질(ACM, Asbestos Containing Material) 결과에 대한 관심이 대두되고 있다. 본 연구에서 는 균질성이 확보된 $\mathrm{ACM}$ 시료를 시야평가법(visual estimation method)과 포인트계수법(point counting method)의 분석결과에 대한 비교·평가를 통하여 분석기관 및 분석자의 신뢰성 향상과 더불어 편광현미 경 분석의 기초자료를 확보고자 하였다. 석면분석은 정성분석과 정량분석으로 구분하였으며, 석면정량을 위한 방법은 EPA 600-R-93-116의 시야평가법과 포인트계수법으로 총 400지점을 계수하는 방법으로 실 시하였다. 먼저 준비된 시료의 균질성을 분산분석을 이용하여 확인한 결과 이상이 없음을 확인하였다. 정
\end{abstract}

Corresponding author

Phone : +82-(0)31-250-2628 Fax : +82-(0)31-250-2629

E-mail : yunho238@gg.go.kr 
성분석의 결과는 백석면과 갈석면으로 확인되었고 정량분석결과는 포인트계수법이 시야평가법과 비교하 여 전체적인 석면함유량이 저평가되는 경향과 함께 포인트계수법은 분석과정이 조금 복잡하고 분석시간 이 많이 소요되었다.

Key words: asbestos, ACM, qualitative analysis, quantitative analysis, visual estimation method, point counting method

\section{1. 서 론}

석면은 천연으로 생산되는 광물 중에서 가격이 저 렴하고, 다른 물질과 결합력이 뛰어나고, 기계적 강도 가 뛰어나며, 불연성, 단열성, 내구성, 절연성, 보온성 이 뛰어나며, 방음, 흡음효과가 다른 물질에 비해 뛰 어난 천연섬유다. 이런 효과로 인하여 슬레이트, 천정 텍스, 밤라이트, 비닐타일, 보온판, 석면보온통, 석면보 온매트, 석면보온토, 석면대, 살포부착 등의 건축자재 로 사용된다. 이외에도 자동차 제동장치, 클러치페이 싱, 선박 난방용, 산업기계부품, 배관의 이음새, 방음 벽 등으로 다양하게 사용되고 있다. ${ }^{1}$

석면은 인체에 노출시 석면폐증, 폐암, 악성중피종을 유발할 수 있는 물질로, 국제암센터(IARC, International Agency for Research on Cancer)에서는 Group 1, 미국 Environmental Protection Agency(EPA)의 통합 유해성 정보시스템(IRIS, Integrated Risk Information System)에 서는 Group A등급의 인체발암물질로 분류하고 있다. 석면의 흡입량에 따라 다르지만 잠복기간을 석면폐증 은 25 40년, 폐암이나 중피종은 15 30년으로 두고 있 어 석면으로 인한 피해증상이 단시간에 나타나지 않 는다. 석면의 종류별 인체 유해성 정도는 청석면 > 갈 석면 > 백석면 순이고, 청석면과 갈석면은 백석면보다 날카롭고 폐에 들어가도 백석면은 어느 정도 용해된 다고 알려져 있으나 청석면은 폐에서 용해되는데 100 년 이상 소요된다. ${ }^{2-3}$

국내에서의 석면원재료 수입은 1995년 88,000톤까 지 약 20년간 꾸준히 증가하였으나 석면으로 인한 피 해사례가 늘면서 1997년부터 청석면과 갈석면의 수입 사용을 금지한 이후 지속적으로 감소하여 2005년 약 6,500톤을 수입하였다. 2009년 석면과 석면함유제품의 사용 - 제조 - 유통 - 수입이 전면금지되기 전까지 약 200 만 톤의 석면 관련 물질이 수입되어 사용된 것으 로 추정하고 있다. ${ }^{4}$

우리나라에 수입된 석면은 주로 건축자재의 원료로 많이 사용되었는데, 1970 년대의 경우 약 $96 \%$ 가 건축
자재인 슬레이트 원료로 사용되었으나, 1990년에는 슬레이트와 보온 단열재 등으로 약 $82.3 \%$, 마찰재인 브레이크 라이닝과 패드 등에 약 $10.5 \%$, 석면 방직제 품인 석면포 등에 약 $5.5 \%$, 그리고 기타 개스킷과 단 열제품에 $1.7 \%$ 가 사용된 것으로 보인다. 최근 자료에 의하면 정부의 일부 예외산업을 제외하고 석면제품 제조 - 수입 · 유통 - 사용금지에 따라 2008년 이전에 비 해 급격히 수입량이 감소하였음을 나타내고 있다. ${ }^{5}$ 특 히 2012년 4월 석면안전관리법 시행에 따라 석면 및 석 면함유 제품에 대한 수입 - 제조 - 사용 등의 금지는 물론 유통 중인 제품의 조사결과에 대한 해당 제품의 회수 및 유통금지까지 명할 수 있도록 규정하였다. ${ }^{6}$ 이러한 석면관리가 엄격히 시행되면서 석면함유물질(ACM, Asbestos Containing Material)로 구분하기 위해 석면분석 의 방법과 평가가 중요한 문제로 대두되고 있다. 석 면 분석방법은 크게 정성평가로 시험물질의 형태 (morphology), 굴절률(refractive index), 다색성(pleochroism), 색깔(color), 복굴절(birefringence), 소광특 성(extinction), 신장율 부호(sign of elongation), 분산염 색의 특성(interference color) 등 섬유나 광물의 광학적 특성분석을 통하여 정성평가를 마친 후 석면이 시험 물질에 얼마나 함유하고 있는지 정량평가로 구분될 수 있는데, 본 연구에서는 사전 자료조사를 통해 확보 된 미지시료(현장시료)를 균질도 평가와 정성평가를 마친 후 정량분석 시 시야평가법(visual estimation method)과 포인트계수법(point counting method)을 비교 · 평가함으로써 두 방법을 통해 분석된 결과값에 대하 여 신뢰성을 평가하고자 한다.

\section{2. 연구방법}

\section{1. 연구물질 선정}

국내 석면사용이 가장 많았던 건축자재 중 미지시 료(현장시료)에서 사전자료조사를 통하여 텍스(texture) 와 분무재(spray coat, 뿜칠재) 총 8 종을 Table 1과 같 이 연구물질로 선정하였다. 또한 석면섬유의 모양과 
Table 1. Type of asbestos by preliminary survey for real world samples

\begin{tabular}{cccc}
\hline \hline Sample ID & Preliminary survey by visual estimation & Material & Note \\
\hline A & $5 \%$ Chrysotile & Texture & Homogeneity test \\
B & $10 \%$ Chrysotile & Texture & - \\
C & $15 \%$ Chrysotile & Texture & - \\
D & $15 \%$ Chrysotile, $3 \%$ Amosite & Texture & - \\
E & $3 \%$ Amosite & Spray Coat & - \\
F & $5 \%$ Amosite & Spray Coat & Homogeneity test \\
G & $10 \%$ Amosite & Spray Coat & - \\
H & $10 \%$ Amosite, $5 \%$ Chrysotile & Spray Coat & - \\
\hline
\end{tabular}

특징을 고려하여 백석면(사문석 계통), 갈석면(각섬석 계통)으로 구분하여 저농도, 고농도 그리고 혼합시료 로 세부시료를 선정하였다. 그리고 추가적으로 2 종에 대하여 정성평가와 정량평가에 앞서 균질도 평가를 위한 대표 검증시료로 이용하였다. 균질도 평가를 위 해서 선정된 2 종의 시료는 핸드 밀(A11B, IKA) 또는 자동 체가름기(Analysette3, FRITSCH)를 이용하여 균 질하게 혼합이 되도록 수차례 작업을 반복하였다.

\section{2. 분석장비}

편광현미경(PLM BX 51, OLYMPUS, JAPAN)은 빛 이 한쪽 방향으로 투과하는 편광을 이용하여 유기 및 무기물질의 광학적 성질을 관찰하는 기기로 구성은 접안렌즈, 상부 편광판, 대물렌즈, 회전 재물대, 수렴 렌즈, 하부 편광판, 조리개, 반사거울 등으로 구성된 현미경을 사용하였다. 편광 현미경(PLM)은 편광의 원 리를 이용하므로 재물대를 기준으로 상부와 하부에 편광판이 각각 하나씩 들어있으며, 광물이나 암석 박 편을 회전시키면서 관찰해야 하므로 재물대가 $360^{\circ}$ 회전이 가능한 장비를 사용하였다. ${ }^{7}$

\section{3. 분석방법}

석면 분석방법은 크게 정성평가와 정량평가로 구분될 수 있는데, 본 연구에서는 시험물질의 광학적 특성을 고 려하여 EPA-600/R-93-116(method for the determination of asbestos in bulk building materials)에 규정된 편광 현미경(PLM)을 이용하여 균질도 평가 후 정성분석 그리고 시야평가법과 포인트계수법에 의해 정량평가 를 수행하였다. ${ }^{8-9}$

2.3.1. 시야평가법(visual estimation method) 시야평가법은 편광현미경을 이용하여 표본 관찰 시 시야 상의 면적을 통해 석면의 함유율을 정량하는 방
법이다. 시야평가법은 결합재 및 충전재의 종류에 따 라 석면이 일정한 비율로 함유된 정량표준시료와 비 교 정량하여 분석의 정확도와 정밀도를 높일 수 있다 .10

\subsection{2 포인트계수법(point counting method)}

포인트계수법은 현미경 대안렌즈의 십자선을 이용 하여 시야에서 십자선의 교차점과 중첩되는 입자 중 석면의 비율을 산출하는 방법이다. 저농도 함유율을 기준으로 분석 시 십자선의 중심과 중첩되는 입자를 최소 400 개 이상 계수한다. 편광현미경(PLM)을 이용 한 포인트계수법 농도의 산출식은 다음과 같다. ${ }^{9-11}$

$$
\begin{aligned}
& \text { 석면 함유율 }(\%)=\frac{\text { 계수된 석면섬유의 개수 }}{\text { 계수된 비어있지 않은 }} \times 100 \\
& \text { 지점의 수(400 points) }
\end{aligned}
$$

\section{4. 시료분석}

\subsection{1. 균질도 평가}

고형시료를 분석하는 과정에서 신뢰성 있는 결과를 얻기 위해서는 무엇보다도 중요한 것은 각 시료에 대 한 균질도 평가에 있다. 따라서 선정된 대표 시료의 균질도를 평가하기 위해 $\mathrm{A}$ 시료, $\mathrm{F}$ 시료를 균질하게 분 쇄하여 10 개의 병입된 시료를 각 시료마다 3 회 반 복 측정하여 평가하였다. 측정방법은 저농도의 석면평 가를 고려하여 편광현미경을 통한 포인트계수법을 이 용하였으며, 균질도에 대한 평가는 일원분산분석 (ANOVA)의 $\mathrm{F}$ 기각치와 $\mathrm{F}$ 비를 비교한 결과값에 대 하여 $\mathrm{F}$ 비가 $\mathrm{F}$ 기각치보다 작으며, $\mathrm{P}$ 값으로부터 $95 \%$ 신뢰수준에서 10 개 시료의 반복측정값에 대한 통계값으로 평가하였다. ${ }^{12-13}$

\subsection{2. 정성평가}

분석시료 정성평가를 위해 사용된 편광현미경은 파 
장을 변화시키는 보정판, 시료를 회전하며 관찰할 수 있는 재물대, 편광기능을 위한 편광판이 갖추어진 장 치로써 대물렌즈와 접안렌즈의 조합으로 400 배의 배 율을 가진 광학적으로 색을 나타나게 하는 분산염색 대물렌즈로 구성된 편광현미경(PLM)을 사용하였다. 연구에 사용된 시료에 대한 백석면, 갈석면 확인은 EPA-600/R-93-116에 규정된 편광현미경을 이용하여 형태, 굴절률, 다색성, 색깔, 복굴절, 소광특성, 신장율 부호, 분산염색의 특성 등 각 석면의 광학적 특성을 비교 · 평가 · 확인하였다. ${ }^{14}$

\subsection{3. 정량평가}

정량평가에 사용된 시야평가법은 시료의 대표적인 부분으로 3 개의 표본을 제작하고, 표본의 전체 면적 을 관찰하여 정량하였다. 일반적으로 시야평가법을 이 용하여 면적대비 관찰되는 석면을 환산한 평가표는 Fig. 1 과 같다. 연구에서 시야평가법과 비교한 포인트 계수법은 총 400 지점을 계수하는 방법으로 실시하였 으며, 하나의 시료에 대해 8 개의 슬라이드를 만들어 분석하였다. 400지점을 계수하기 위해 편광현미경에 삽입하여 사용되는 counting reticule은 Fig. 2와 같다. 정량평가는 1 개의 슬라이드당 50 개 지점을 계수하
여 십자선에 겹치는 물질이 있을 때 1 개의 지점으로 계수하며, 전체 400지점 중 계수 된 석면섬유의 수로 나누어 계산한다. ${ }^{9.11}$

\section{3. 결과 및 고찰}

\section{1. 균질도 평가 결과}

$\mathrm{A}$ 시료, $\mathrm{F}$ 시료의 균질도를 평가하기 위해 일원분산 분석(ANOVA)의 $\mathrm{F}$ 기각치와 $\mathrm{F}$ 비를 비교하여, $\mathrm{P}$ 값 으로부터 $95 \%$ 신뢰수준에서 균질도를 통계값으로 평 가하였으며, 그 포인트계수법의 분석값은 Table 2에 요약하였다. 일원분산분석법의 통계적 원리를 이용한 $\mathrm{A}$ 시료의 균질도 평가 결과 $\mathrm{F}$ 비 $=2.079<\mathrm{F}$ 기각치 $=$ 2.393 이므로 $95 \%$ 신뢰수준에서 균질함을 Table 3에 서 확인할 수 있다. $\mathrm{F}$ 시료 또한 $\mathrm{F}$ 비 $<\mathrm{F}$ 기각치 이 므로 균질도 평가를 위해 선정된 시료는 모두 균질함 을 Table 3에서 확인하였다. ${ }^{15-16}$

\section{2. 정성평가 결과}

연구를 위해 선정된 총 8 종에 대하여 EPA-600/R93-116에 규정된 편광현미경을 이용한 섬유나 광물의 광학적 특성분석을 통하여 정성분석을 수행한 결과
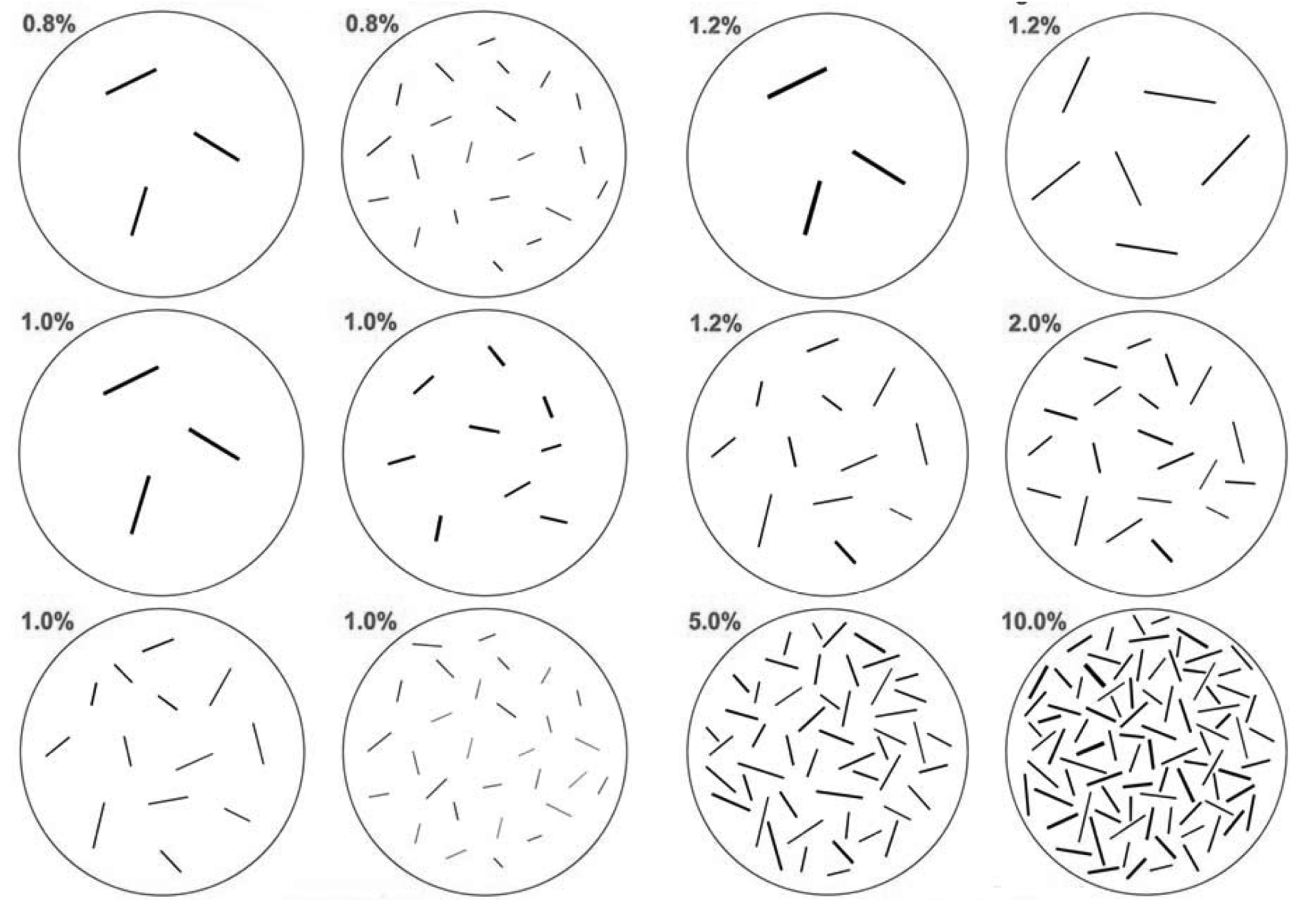

Fig. 1. Area \% charts black on white Reference: Shu-Chun Su, Assuming the field of view is filled with matrix materials, 2004. 
Table 2. Analysis results of homogeneity

\begin{tabular}{|c|c|c|c|c|}
\hline \multirow{2}{*}{ Sample ID, A } & \multicolumn{3}{|c|}{ Times of measurement } & \multirow{2}{*}{ Method } \\
\hline & 1 & 2 & 3 & \\
\hline A-1 & 2.75 & 3.50 & 3.25 & \multirow{26}{*}{ PLM } \\
\hline A-2 & 3.00 & 3.75 & 3.50 & \\
\hline A-3 & 3.75 & 3.25 & 3.25 & \\
\hline A-4 & 2.50 & 3.00 & 2.75 & \\
\hline A-5 & 3.50 & 3.25 & 3.50 & \\
\hline A-6 & 3.75 & 3.00 & 3.00 & \\
\hline A-7 & 2.50 & 3.50 & 3.50 & \\
\hline A-8 & 3.75 & 3.75 & 3.75 & \\
\hline A-9 & 3.25 & 3.50 & 3.25 & \\
\hline A-10 & 3.00 & 3.25 & 2.50 & \\
\hline Ave & 3.18 & 3.38 & 3.23 & \\
\hline Stdev & 0.50 & 0.27 & 0.38 & \\
\hline \multirow{2}{*}{ Sample ID, F } & \multicolumn{3}{|c|}{ Times of measurement } & \\
\hline & 1 & 2 & 3 & \\
\hline F-1 & 2.75 & 3.25 & 3.25 & \\
\hline F-2 & 4.00 & 4.25 & 3.75 & \\
\hline F-3 & 3.75 & 3.00 & 4.00 & \\
\hline $\mathrm{F}-4$ & 3.00 & 3.50 & 2.75 & \\
\hline F-5 & 3.50 & 3.50 & 3.50 & \\
\hline F-6 & 3.75 & 3.75 & 3.25 & \\
\hline F-7 & 3.00 & 2.75 & 3.75 & \\
\hline F-8 & 3.25 & 3.00 & 3.75 & \\
\hline F-9 & 4.00 & 3.75 & 3.50 & \\
\hline $\mathrm{F}-10$ & 2.75 & 4.00 & 3.25 & \\
\hline Ave & 3.38 & 3.48 & 3.48 & \\
\hline Stdev & 0.49 & 0.48 & 0.36 & \\
\hline
\end{tabular}

백석면(3 종), 갈석면(3 종), 혼합시료(2 종, 백석면+ 갈석면)로 확인되었다. 백석면(A시료, $\mathrm{B}$ 시료, $\mathrm{C}$ 시료), 갈석면(E시료, $\mathrm{F}$ 시료, $\mathrm{G}$ 시료)와 혼합시료(D시료, $\mathrm{H}$ 시
료)의 광학적 특징을 확인한 결과는 Table 4와 같다.

\section{3. 정량평가 결과}

석면의 정량평가를 위해 선정된 $\mathrm{A}$ 시료 $\mathrm{H}$ 시료에 대 한 시야평가법과 포인트계수법을 이용하여 분석한 결 과 Table 5와 같다. 분석결과의 신뢰성 검증을 위하여 환경분야에서 적용되는 공정시험기준에 의해 두 시료 의 측정값 차 $\left(\mathrm{C}_{2}-\mathrm{C}_{1}\right)$ 를 두 시료 측정값의 평균값 $(\mathrm{X})$ 으 로 나눈 상대편차백분율(RPD, Relative Producibility Deviation)에 대한 결과값 또한 Table 5에 나타내었다. ${ }^{17}$

$$
\text { 상대편차백분율 }(\%)=\frac{C_{2} \times C_{1}}{\bar{x}} \times 100 \%
$$

두 시험방법의 상대편차백분율(RPD)은 26 82\% 까 지 편차를 나타내었으며, 연구를 시작할 때 시료의 균 질성이 확보된 시료에 한하여 내부 신뢰성 검증을 위 하여 EPA-600/R-93-116/038a(quality assurance handbook) 외 국내 - 외 석면분석기관에서 일반적으로 설정하였던 상대편차백분율(RPD), $100 \%$ 이하에 대한 결과값 또 한 만족하였다. 두 방법에 따른 결과값의 비교는 포인 트계수법은 동일 농도에 대하여 시야평가법 보다 저 평가 되는 경향과 함께 전처리가 복잡하고 분석시간 이 많이 소요된다. 그리고 시야평가법과 포인트계수법 을 이용하여 분석한 결과의 비교차이를 그래프로 나 타내면 Fig. 3과 같다.

\section{4. 연구결과와 EPA기준 비교}

미국의 대표적인 석면관리 기관인 $\mathrm{EPA}$ (Environmental Protection Agency)에서는 분석자의 정확한 석 면평가를 위해서 Table 6과 같이 편광현미경을 이용한 일반적인 정량분석 허용오차를 권고하고 있다. ${ }^{18}$

Table 3. Evaluation results of homogeneity

\begin{tabular}{|c|c|c|c|c|c|c|}
\hline \multicolumn{7}{|c|}{ Sample ID, A } \\
\hline Source of variation & SS & df & MS & $\mathrm{F}$ ratio & P-value & $F$ crit \\
\hline Between groups & 2.144 & 9 & 0.238 & 2.079 & 0.083 & 2.393 \\
\hline Within groups & 2.292 & 20 & 0.115 & & & \\
\hline Total & 4.435 & 29 & & & & \\
\hline \multicolumn{7}{|c|}{ Sample ID, F } \\
\hline Source of variation & SS & df & MS & $F$ ratio & P-value & $\mathrm{F}$ crit \\
\hline Between groups & 2.419 & 9 & 0.269 & 1.767 & 0.138 & 2.393 \\
\hline Within groups & 3.042 & 20 & 0.152 & & & \\
\hline Total & 5.460 & 29 & & & & \\
\hline
\end{tabular}

SS: sum of squares, df: degree of freedom, MS: mean squares 
158 Yun-Ho Choi, Tae-Hwa Kim, Yong-Soo Bae, Tae-Hyun Kim, Hyeon-Ja Kim, Eun-Ah Jang and Beom-Goo Hwang

Table 4. Optical properties of asbestos

\begin{tabular}{lcc}
\hline \hline \multirow{2}{*}{ Character of asbestos } & & Description \\
\cline { 2 - 3 } & Chrysotile & Amosite \\
\hline Morphology & Wavy, Silky, Curly Fibers & Straight, Needles \\
Aspect ratio & $>3: 1$ & $>3: 1$ \\
Color & Colorless, White & Colorless, Light gray \\
Pleochroism & None & None \\
Extinction type & Parallel & Usually parallel \\
Refractive index & $1.530 \sim 1.575$ & $1.664 \sim 1.686$ \\
Birefringence & Law & Moderate \\
Sign of eongation & + & + \\
RI Liquid, Color & 1.550 HD, Blue - Magenta & 1.680, Golden yellow - Blue \\
Qualitative analysis & $\mathrm{A}, \mathrm{B}, \mathrm{C},(\mathrm{D}),(\mathrm{H})$ & $\mathrm{E}, \mathrm{F}, \mathrm{G},(\mathrm{H}),(\mathrm{D})$ \\
\hline
\end{tabular}

Table 5. Percent asbestos by visual estimation and point counting method for real world samples

\begin{tabular}{cllcr}
\hline \hline \multirow{2}{*}{ Sample ID } & \multirow{2}{*}{ Types of asbestos } & \multicolumn{2}{c}{ Asbestos concentration } & \multirow{2}{*}{ RPD } \\
\cline { 3 - 4 } & & \multicolumn{1}{c}{ Visual estimation } & Point counting & $47 \%$ \\
A & Chrysotile & $6 \%$ Chrysotile & $3.50 \%$ Chrysotile & $32 \%$ \\
B & Chrysotile & $10 \%$ Chrysotile & $7.25 \%$ Chrysotile & $26 \%$ \\
C & Chrysotile & $13 \%$ Chrysotile & $10.25 \%$ Chrysotile & $43 \%$ \\
D & Chrysotile, Amosite & $13 \%$ Chrysotile, $4 \%$ Amosite & $9.75 \%$ Chrysotile, $1.25 \%$ Amosite & $82 \%$ \\
E & Amosite & $3 \%$ Amosite & $1.25 \%$ Amosite & $54 \%$ \\
F & Amosite & $6 \%$ Amosite & $3.25 \%$ Amosite & $62 \%$ \\
G & Amosite & $12 \%$ Amosite & $6.50 \%$ Amosite & $46 \%$ \\
H & Amosite, Chrysotile & $11 \%$ Amosite, $5 \%$ Chrysotile & $6.25 \%$ Amosite, $4.00 \%$ Chrysotile & $46 \%$ \\
\hline
\end{tabular}

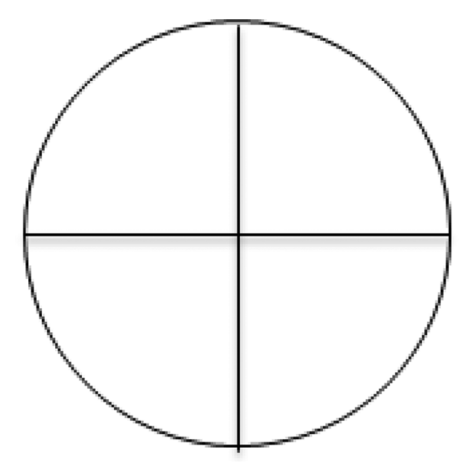

Fig. 2. Counting reticule for cross-hair.

$\mathrm{EPA}$ 에서 제시한 허용오차를 바탕으로 두 분석방법 에 대하여 비교한 결과 석면분석의 한 특징으로 논의 되고 있는 석면정량분석의 정량분석 허용오차 범위에 만족하는 결과를 얻었다. 즉 시야평가법을 이용하여 분석한 A시료의 결과값 $(6 \%)$ 과 포인트계수법의 결과 값 $(3.50 \%)$ 을 Table 6.에서 제시한 오차범위로 환산하

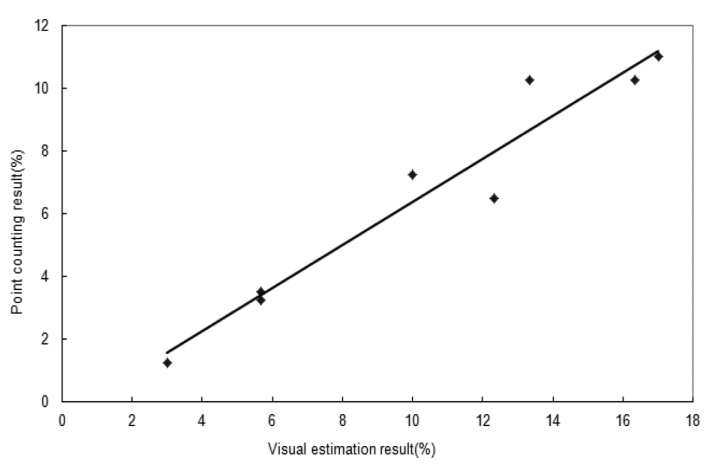

Fig. 3. Graphical illustration of results for asbestos concentration.

여 비교하면 1 10\%에 포함됨을 확인할 수 있다. 같은 방법으로 두 분석방법의 모든 결과값에 대하여 EPA 오차범위와 비교한 결과 만족하는 수준을 나타내었다. 이것은 연구의 본 목적인 균질성이 확보된 시료를 통 하여 정성평가 후 서로 다는 두 시험방법을 이용한 정량분석 허용오차를 만족하므로 분석자 및 분석기관 
Table 6. Suggested acceptable errors for PLM analysis (Based on 400 point count of reasonably homogeneous sample or 100 fields of view for visual estimate)

\begin{tabular}{cccc}
\hline $\begin{array}{c}\text { \% Area } \\
\text { asbestos }\end{array}$ & $\begin{array}{c}\text { Acceptable } \\
\text { mean result }\end{array}$ & $\begin{array}{c}\text { \% Area } \\
\text { asbestos }\end{array}$ & $\begin{array}{c}\text { Acceptable } \\
\text { mean result }\end{array}$ \\
\hline 1 & $>0 \sim 3 \%$ & 50 & $40 \sim 60 \%$ \\
5 & $>1 \sim 9 \%$ & 60 & $50 \sim 70 \%$ \\
10 & $5 \sim 15 \%$ & 70 & $60 \sim 80 \%$ \\
20 & $10 \sim 30 \%$ & 80 & $70 \sim 90 \%$ \\
30 & $20 \sim 40 \%$ & 90 & $80 \sim 100 \%$ \\
40 & $30 \sim 50 \%$ & 100 & $90 \sim 100 \%$ \\
\hline
\end{tabular}

Table 7. Analysis of results and EPA error

\begin{tabular}{|c|c|c|c|c|}
\hline \multirow[b]{2}{*}{ Sample ID } & \multicolumn{2}{|c|}{ Concentration(\%) } & \multirow{2}{*}{$\begin{array}{c}\text { Calculated } \\
\text { EPA error } \\
\text { range }\end{array}$} & \multirow[b]{2}{*}{ Note } \\
\hline & $\begin{array}{c}\text { Visual } \\
\text { estimation }\end{array}$ & $\begin{array}{c}\text { Point } \\
\text { counting }\end{array}$ & & \\
\hline A & 6 & 3.50 & $1 \sim 10 \%$ & Satisfied \\
\hline B & 10 & 7.25 & $5 \sim 15 \%$ & Satisfied \\
\hline $\mathrm{C}$ & 13 & 10.25 & $7 \sim 20 \%$ & Satisfied \\
\hline D & 17 & 11.00 & $9 \sim 26 \%$ & Satisfied \\
\hline E & 3 & 1.25 & $>1 \sim 7 \%$ & Satisfied \\
\hline $\mathrm{F}$ & 6 & 3.25 & $1 \sim 10 \%$ & Satisfied \\
\hline $\mathrm{G}$ & 12 & 6.50 & $6 \sim 18 \%$ & Satisfied \\
\hline $\mathrm{H}$ & 16 & 10.25 & $8 \sim 24 \%$ & Satisfied \\
\hline
\end{tabular}

은 두 시험방법 중 시료의 상태와 전처리과정에 따라 선택사용이 가능하다는 것을 의미한다. 결론적으로 서 로 다른 두 시험방법인 시야평가법과 포인트계수법을 통하여 얻은 결과값에 대한 큰 차이는 없다는 것을 의미한다. 비교결과는 Table 7에 나타내었다.

\section{4. 결 론}

편광현미경을 사용하여 시야평가법과 포인트계수 법을 이용하여 각 시료의 균질도, 정성평가, 정량평가 를 연구한 결과는 다음과 같다.

1. 대표시료(A시료, F시료)를 이용하여 각각의 농도 별 균질도를 편광현미경을 사용하여 측정한 결과 일 원분산법의 $\mathrm{F}$ 기각치보다 $\mathrm{F}$ 비가 작으므로, $95 \%$ 신 뢰 수준에서 연구에 사용된 시료는 균질함을 확인할 수 있었다.

2. 본 연구에서 선정된 8 종에 시료에 대하여 형태, 굴절률, 다색성, 색깔, 복굴절, 소광특성, 신장율 부호, 분산염색의 특성 등 광학적 특성분석을 통하여 정성 평가 한 결과 백석면(3 종), 갈석면(3 종), 혼합시료(2
종, 백석면+갈석면)로 확인되었다.

3. 정량분석을 위해 사용되었던 시야평가법과 포인 트계수법을 비교하면 포인트계수법은 시야평가법에 비교하여 전체적인 석면함유량이 저평가되었다. 그리 고 시야평가법은 전처리 및 결과산출에 빠른 장점을 보인 반면 포인트계수법은 전처리가 복잡하고 분석시 간이 많이 소요되었다.

4. 균질성이 확보된 시료를 통하여 분석한 결과값에 대하여 시야평가법과 포인트계수법은 모두 $\mathrm{EPA}$ 에서 제시한 정량분석 허용오차를 만족하므로 분석자 및 분석기관은 두 시험방법 중 시료상태와 전처리 과정 에 따라 선택사용이 가능하며 두 분석방법의 결과값 에 대한 큰 차이가 없다는 것을 확인하였다.

5. 연구를 통해 확인된 두 분석방법의 비교를 통하 여 분석자 및 분석기관은 특히 정량평가를 요하는 시 료에 대하여 보다 정확한 석면분석이 가능하고 분석 자는 스스로 분석한 결과값을 두 방법의 범위와 비교 평가를 통해 분석능력 향상 및 결과에 대한 신뢰성을 향상시킬 수 있을 것으로 기대된다.

\section{Reference}

1. H. W. Kim, G. Y. Park, J. G Han, Y. S. Han, B. G. Hwang, J. H. Lee, Releasing of asbestos fibers from the weathered asbestos cement slate roofing, The Korean Industrial Hygie, 20(2), 88-93 (2010).

2. U.S. Geological Survey, Mineral Commodity Summaries, 2007.

3. Becklake, Mr. American Review of Respiratory Disease, Asbestos-related diseases of the lung and other organs, 187-227 (1976).

4. J. K. Choi, D. Y. Paek, N. W. Paik, The Production, the Use, the Number of Workers and Exposure Level of Asbestos in Korea, The Korean Industrial Hygie, 8(2), 242-243 (1998).

5. KONETIC, Bans of Asbestos Import, 2006.

6. Ministry of Environment, Control of Asbestos Regulations, 2012.

7. NIER, Method for the determination of Asbestos in Waste, 2007.

8. EPA 600-R-93-116, Method for the determination of asbestos in bulk building materials, 1993.

9. EPA-600/M-82-020 : Interim method for the determination of asbestos in bulk insulation samples, 1982. 
160 Yun-Ho Choi, Tae-Hwa Kim, Yong-Soo Bae, Tae-Hyun Kim, Hyeon-Ja Kim, Eun-Ah Jang and Beom-Goo Hwang

10. Department of Labor, Asbestos Survey and QA/QC Manual, 2009.

11. RTI, RTI Calibration Standard No. 1 INFORMATION SHEET, 2009.

12. SO Guide 34, General requirements for the competence of reference material producers, 2009.

13. ISO Guide 30, Terms and definitions used in connection with reference materials, 1992.

14. Agency for Technology and Standards, KS L 5300,
Determination of Asbestos in Bulk Material, 2009.

15. ISO Guide 35, Reference materials-general and statistical principles for certification, 2006.

16. ISO/IEC 17025, General requirements for the competence of testing and calibration laboratories, 2005.

17. Ministry of Environment, Official Test Methods of Soil Quality, 2009.

18. McCrone Research Institute, Advanced Asbestos Identification, APPENDICES, 2005. 